\title{
A Sample Case of Treatment of a Preadolescent with Pervasive Developmental Disorder in Milan in 2013
}

\section{Scognamiglio Riccardo Marco ${ }^{1 *}$, Russo Simone Matteo ${ }^{2}$, Zerbini Carlo Alberto $^{3}$, Colombini Donata ${ }^{2}$ and Fumagalli Matteo ${ }^{3}$}

${ }^{1}$ Psychologist Psychotherapist, Scientific Director, Istituto di Psicosomatica Integrata, Milan, Italy

${ }^{2}$ Psychologist Psychotherapist, Istituto di Psicosomatica Integrata, Milan, Italy

${ }^{3}$ Clinical Psyhcologist, Istituto di Psicosomatica Integrata, Milan, Italy

*Corresponding Author: Scognamiglio Riccardo Marco, Psychologist

Psychotherapist, Scientific Director, Istituto di Psicosomatica Integrata, Milan, Italy.
Received: January 27, 2020;

Published: February 21, 2020

(C) All rights are reserved by Scognamiglio

Riccardo Marco., et al.

DOI: 10.31080/ASPE.2020.03.0227

\begin{abstract}
Objective: The aim of the study is to evaluate the effects of a model of therapeutic intervention, called Integrated Psychosomatic Model, based on a sensorimotor training to improve cognitive performance and perceptual abilities in a single case of Autism Spectrum Disorder (ASD).

Methods: In order to evaluate the effectiveness of the treatment specifically addressed to the body, which lasted weekly for 4 months plus a one-year follow-up, the therapists carried out psychometric evaluations in six different time points (T0, T1, T2, T3, T4, T5). To evaluate the level of development of the subject in relation to cognition, motility, and maladjusted behavior we used PEP3, and to evaluate the body changes for what concerns the perceptive abilities the TPV.

Results: The results of the treatment based on a bodily mediation showed a striking improvement in all the composite scores of PP3; on the contrary, for what concerns the body changes, the TPV showed a significant increase of the visual-motor integration index which increases from "very poor" to "in the average". The follow-up data (T4) after four months confirmed the achieved scores, therefore strengthening the affective-cognitive and motor abilities gained by the subject during the treatment.

Conclusion: The evaluation of the intervention confirms, for those subjects with a compromised symbolic-visual elaboration and mediation, the effectiveness of using the body as a changing instrument in psychotherapy.

Keywords: Autism Spectrum Disorders (ASD), bodyworks, sensorimotor, Integrated Psychosomatic Model
\end{abstract}

\section{Introduction}

The research has been carried out in collaboration with the Department of Psychology of University of Milano-Bicocca. It's aim was to verify the effect of the Integrated Psychosomatic Model psychotherapeutic intervention, with a sensorimotor training on a pre-adolescent patient with ADS. Specifically, the objective was to show how the use of the body could be a changing tool in multiple clinical settings.

We wanted to verify improvements in body skills (global motility, visual-perceptive skills, visual-motor coordination), not otherwise achieved during previous treatments (cognitive therapy, facilitated communication, speech therapy, psychomotricity), as well as assessing the cognitive skills related to the communicative and affective-relational sphere.
The Integrated Psychosomatic Model [1,2] has sprung from the blending of psychodynamic psychotherapy and affective neuroscience [3], with a precise focus on the patient's body as a mediator of everything that can't be inscribed in the verbal and symbolic system of language and conscious representation [4].

Specifically, it was found particularly effective with patients suffering from mentalization deficits, affective regulation disorders, organic disorders and alexithymia, conditions notoriously resistant to the classic "talking cure" [5].

The Autism Spectrum Disorders (ASD), among others, are perfectly placed in the range described by the aforementioned deficits, having these patients mentalization deficits, as well as difficulties in the emotional sphere (empathy), and being often conditioned by declinations of suffering in their own body [6]. 
In the clinical practice with these patients, despite evidence regarding the biological basis of the disorder, it seems useful to use the body as a necessary work tool in the psychotherapeutic treatment [7].

The main assumption of the Integrated Psychosomatic Model is that the body is the prime mover of any type of symbolization [8], and that therefore it is necessary to start right from the body, when it comes to communicative and emotional disorders, especially when the patient's deficits rise during development, as in the case of ASD. The body thus becomes an instrument of relationship, on which to tune in, dialogue, and acquire new awareness.

\section{Materials and Methods \\ Methods}

The research is a single case on a preadolescent patient of 11 years and 2 months, evaluated at five different time points (T0, T1, T2, T3, T4), along a four-month time frame plus a follow-up appraisal one year after T0 (T5). The patient has been treated according to Integrated Psychosomatic Model. The evaluations were carried out on a weekly basis, with two follow-up evaluations after the treatment ended.

The following scales have been used:

- $\quad$ The Psycho Educational Profile 3 (PEP3) to appraise the patients' developmental level of areas as cognition, motricity and unfitting behaviour;

- The Developmental Test of Visual Perception (TPV) in order to measure bodily changes in the perceptive abilities;

- The PEP3 semi-structured interview has been submitted to the patient's parents, in order to appraise adaptive behaviours to social life, personal autonomy, cognitive abilities and affective-relational competences outside the therapeutic context.

The sensorimotor training was based on a repetition of specific stereotypic infants movements (cross-crawl), followed by fine motor exercises and multisensory activities [9]. The former emphasizes gross motor skills like balance, posture and a correct inter-hemispheric integration. The latter puts effort into vestibular stimulation, eye tracking, eye-hand coordination and visual-motor cross-pattern [10]. Overall, the program includes fetal and neonatal movements which trace the stereotypic movements of primary and postural reflexes.

The treatment's setting was a center of clinical psychology (Istituto di Psicosomatica Integrata) with two different therapists. The young patient has been treated for four months on a weekly basis. The treatment was carried out from January 2012 to May 2012, with a follow-up in January 2013.

\section{Data analysis}

Statistic analysis were carried out with SPSS or plus software.

\section{Results}
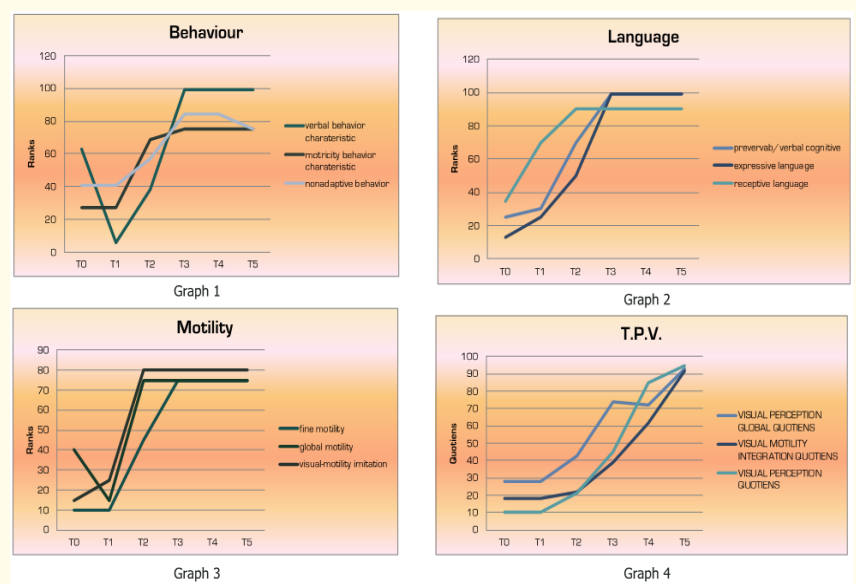

\begin{tabular}{|c|c|c|c|c|c|c|}
\hline \multicolumn{7}{|c|}{ PEP3 } \\
\hline & то & T1 & т2 & T3 & T4 & T5 \\
\hline CVP & Moderate & moderate & moderate & slight & normal & normal \\
\hline LE & grave & slight & moderate & moderate & normal & normal \\
\hline$L R$ & moderate & grave & slight & normal & normal & normal \\
\hline MF & grave & grave & grave & moderate & normal & normal \\
\hline MG & moderate & moderate & grave & slight & normal & normal \\
\hline IVM & grave & moderate & moderate & normal & normal & normal \\
\hline $\mathrm{EE}$ & moderate & normal & moderate & slight & normal & normal \\
\hline RS & slight & normal & normal & normal & normal & normal \\
\hline смс & moderate & grave & normal & normal & slight & normal \\
\hline cve & moderate & moderate & grave & moderate & normal & normal \\
\hline c & moderate & grave & moderate & slight & normal & normal \\
\hline$M$ & moderate & moderate & grave & slight & normal & normal \\
\hline CD & moderate & moderate & moderate & moderate & normal & normal \\
\hline
\end{tabular}

Table 1

\section{Discussion}

Usually, the sensorimotor training is submitted to children with developmental coordination disorder (DCD) [11] as well as to children with attentional or motor difficulties [12]. In children with neurological or neurodevelopmental conditions, vestibular disorders may be comorbid with the primary condition [13]. Research on motor impairments has suggested that children with ASD have substantial deficits in basic motor control skills, as well as specific impairments in praxis [14]; that being the reason why it could be useful a vestibular rehabilitation to improve postural control, balance and gait [15]. Sensorimotor experiences reliably enhance dendritic branching, synaptic density, and neurogenesis [16].

In ASD, Environmental Enrichment Therapy, which uses a set of sensorimotor exercises similar to those used in Integrated Psychosomatic Model, shows significant improvements both in the cognitive ability and in the autism symptom's severity [17]. Moreover, this kind of therapy seems to be more effective than behavioral treatments for 4-7-years-old children [18]. For example, Woo and Leon [19] show that after 6 months of Environmental Enrichment 
Therapy, submitted to a group of male children diagnosed with autism (3-12 years old), the mean change in Leiter-R (Visualization and Reasoning) raw scores in the sensorimotor enrichment group was 11.3 points higher than that in the standard care group.

The results of our sensorimotor training (from T0 to T3) have shown an evident improvement in all the composite scores of the PEP3, as confirmed by the analysis of the ranks and the significance of the figures of test $\mathrm{C}^{1}$, concerning the cognitive-verbal area.

For what concerns the bodily changes, the TPV shows an evident increase in all the quotients, whose descriptive evaluations pass from "very poor" to "average" figures.

In the four months follow-up appraisal (T4), a statistically relevant confirmation of the achieved improvements in all the previously evaluated areas has been noticed with test C.

Further, in the subsequent one year follow-up (T5), the results show a statistically relevant consolidation, in the long run of the bodily abilities, of the cognitive and communicative skills and of the affective-relational competences (Graph 1, 2, 3, 4 and Table 1).

Finally, through a questionnaire supplied to his parents in T3 concerning the echological behaviours daily carried out by the boy, i.e. those referring to personal autonomy and to social life, we have noticed an external confirmation of the improvements achieved during treatment, improvements therefore generalized from therapeutic context to daily life.

\section{Conclusion}

The results seem to confirm the clinical hypotheses at the basis of the Integrated Psychosomatic Model. The body may become a transformative instrument by promoting quantitative and qualitative changes in subjects with dysfunctions in the symbolic area, e.g. in developmental disorders. The body focused treatment of the Integrated Psychosomatic Model improves the body's regulation ability, the cognitive and communicative skills as shown by the affective-emotional nuances of the speech, no longer stereotyped, and, in the final phases of treatment, the appearance of dreams, for the very first time.

This study is born as an action research project, but the single case design has its limits. The following step should be an expansion of the Integrated Psychosomatic Model treatment to a group of children with ASD.

A second facet is that the Integrated Psychosomatic Model has its focus on the relationship between the patient and the thera- pist. For this reason, the techniques of the sensorimotor training become an instrument to encourage the engagement between the therapist and the child. In particular the body touch allowed to regulate the altered emotions and to share positive affects.

The application of psychosomatic techniques within a significant attuned relationship, favored the mind-body connections and the symbolization process, letting the patient pass from a concrete type of thinking to a more abstract-symbolic type.

We assume that, with ASD, a treatment which puts together the focus on the relationship and the sensorimotor enrichment is more effective than intensive behavioral approaches. The effectiveness is given by the use of the body as a communication channel, or rather a relational bridge. The treatment's results were consolidated over time and have shown a better adaptation of the young boy in everyday life.

\section{Bibliography}

1. Scognamiglio RM. "Il male in corpo. La prospettiva somatologica nella psicoterapia della sofferenza del corpo". Milano: FrancoAngeli (2008).

2. Scognamiglio RM. "Psicologia psicosomatica. L'atto psicologico tra codici del corpo e codici della parola". Milano: FrancoAngeli (2016).

3. Panksepp J. "Affective neuroscience: The foundations of human and animal emotions". Oxford university press (2004).

4. Scognamiglio RM., et al. "Somatic Intelligence: a new perspective of metacognitive tool?" Psychotherapy and Psychosomatics 82 (2013): 1-134.

5. Bucci W. "When Language Fails: A Psychoanalytic Appraisal of Alexithymic Disorders". Psyccritiques 35.2 (1990): 147-148.

6. Frith U. "Autism: Explaining the enigma". Blackwell Publishing (2003).

7. Levy SE and Hyman SL. "Complementary and alternative medicine treatments for children with autism spectrum disorders". Child and Adolescent Psychiatric Clinics 17.4 (2008): 803-820.

8. Pulvermüller F. "Semantic embodiment, disembodiment or misembodiment? In search of meaning in modules and neuron circuits". Brain and language 127.1 (2013): 86-103.

9. Clearfield MW. "The role of crawling and walking experience in infant spatial memory". Journal of Experimental Child Psychology 89.3 (2004): 214-241.

${ }^{1}$ The «test $\mathrm{C} »$ : a statistical model for the clinical and experimental analysis of data in time series related to a single subject. 
10. Evanoff JN and Lackner JR. "Some proprioceptive influences on the spatial displacement component of the oculogyral illusion". Perception and Psychophysics 43.6 (1988): 526-530.

11. Niklasson M., et al. "Catching-up: Children with developmental coordination disorder compared to healthy children before and after sensorimotor therapy". PloS One 12.10 (2017): e0186126.

12. Niklasson M., et al. "Sensorimotor therapy: using stereotypic movements and vestibular stimulation to increase sensorimotor proficiency of children with attentional and motor difficulties". Perceptual and Motor Skills 108.3 (2009): 643-669.

13. Ghai S., et al. "Prevalence of Vestibular Dysfunction in Children With Neurological Disabilities: A Systematic Review". Frontiers in Neurology 10 (2019): 1294.

14. Fournier KA., et al. "Motor coordination in autism spectrum disorders: a synthesis and meta-analysis". Journal of Autism and Developmental Disorders 40.10 (2010): 1227-1240.

15. Melo RS., et al. "Vestibular rehabilitation exercises programs to improve the postural control, balance and gait of children with sensorineural hearing loss: A systematic review". International Journal of Pediatric Otorhinolaryngology (2019): 109650.

16. Nithianantharajah J and Hannan AJ. "Enriched environments, experience-dependent plasticity and disorders of the nervous system". Nature Reviews Neuroscience 7.9 (2006): 697-709.

17. Aronoff E., et al. "Environmental enrichment therapy for autism: outcomes with increased access". Neural Plasticity 350.23 (2016): e2734915.

18. Eikeseth S., et al. "Intensive behavioral treatment at school for 4-to 7-year-old children with autism: A 1-year comparison controlled study". Behavior Modification 26.1 (2002): 49-68.

19. Woo CC and Leon M. "Environmental enrichment as an effective treatment for autism: a randomized controlled trial". Behavioral Neuroscience 127.4 (2013): 487.

\section{Assets from publication with us}

- Prompt Acknowledgement after receiving the article

- Thorough Double blinded peer review

- Rapid Publication

- Issue of Publication Certificate

- High visibility of your Published work

Website: www.actascientific.com/

Submit Article: www.actascientific.com/submission.php

Email us: editor@actascientific.com

Contact us: +919182824667

Citation: Scognamiglio Riccardo Marco., et al. "A Sample Case of Treatment of a Preadolescent with Pervasive Developmental Disorder in Milan in 2013". Acta Scientific Paediatrics 3.3 (2020): 62-65. 